\title{
Course Coordinators' Beliefs, Attitudes and Motivation and their Relation to Self-Reported Changes in Technology Integration at the Open University of Israel
}

\author{
Eva Guterman, Yael Alberton, Relly Brickner, and Ronit Sagi \\ Open University of Israel, Raanana, Israel
}

\section{evagu@openu.ac.il; yaelal@openu.ac.il; rellybr@openu.ac.il; ronitsa@openu.ac.il}

\begin{abstract}
This study investigates the relationship between the beliefs, attitudes, and motivation of course coordinators at the Open University of Israel regarding the integration of technology into teaching processes and their self-reported changes as a result of the integration into academic teaching. An electronic survey was sent to 285 course coordinators employed during the spring semester of 2007,128 of whom responded ( $45 \%$ response rate). The results show that the "belief index" in the potential of technology integration into teaching is higher than the "skepticism index," and the enhancing (internal and external) factors underlying the decision to implement technology outweigh the inhibiting factors. Different patterns of correlation between internal and external factors and changes in teaching were found and discussed.
\end{abstract}

Keywords: ICT, academic teaching, attitudes, beliefs and motivation, technology integration in teaching, enhancing and inhibiting factors

\section{Introduction}

The Open University of Israel (OUI), a distance learning university, makes use of advanced technologies to improve its distance teaching, which provide students with a wealth of learning materials and continuous contact with teaching staff and other students. Most OUI courses have websites that are an integral part of the learning and teaching environment. In April 1995, the University established Shoham (the Hebrew acronym for "Distance Learning Methods"). Shoham deals with the research, development, evaluation, and integration of technology-based pedagogical solutions to meet the varied needs of academic courses offered by the OUI. Shoham was actively involved in the development of an Internet-based learning environment, OPUS, which serves as

Material published as part of this publication, either on-line or in print, is copyrighted by the Informing Science Institute. Permission to make digital or paper copy of part or all of these works for personal or classroom use is granted without fee provided that the copies are not made or distributed for profit or commercial advantage AND that copies 1) bear this notice in full and 2) give the full citation on the first page. It is permissible to abstract these works so long as credit is given. To copy in all other cases or to republish or to post on a server or to redistribute to lists requires specific permission and payment of a fee. Contact Publisher@InformingScience.org to request redistribution permission. the infrastructure for the University's course websites. An OUI course website may include, among others, study materials, links to databases and internet sites related to the subject matter of the course, multimedia materials and learning aids, as well as tools for communication among all the participants in the teaching/learning process - students and teaching teams. Shoham also offers

\section{Editor: Alex Koohang}

An earlier, shorter version of this paper was presented at the Chais conference 2009, in Raanana, Israel, and included in Y. Eshet-Alkalai, A. Caspi, S. Eden, N. Geri, \& Y. Yair (Eds.), Proceedings of the Chais conference on instructional technologies research 2009: Learning in the technological era. Raanana: The Open University of Israel. http://www.openu.ac.il/research center eng/conferences.html 
training and support for the teaching staff, who integrate technologies into their teaching.

In Open University courses, course coordinators (CCs) are responsible for the academic and administrative planning and implementation of all course activities, including computer-mediated activities. As such, decisions concerning the use of technology in teaching and the ways that technology is incorporated into the teaching are in their hands. The current study is part of a larger evaluation study aimed at analyzing the nature and essence of the integration of technology into academic teaching processes at the OUI, from the perspective of the CCs (Guterman, Alberton, Brickner, \& Sagi, 2008). The study investigated the relationship between the beliefs, attitudes, and motivation of the CCs at the OUI regarding technology integration and the changes in their activities and experiences in light of its implementation.

\section{Theoretical Background}

The process of ICT implementation is one of mutual interaction between technology and the social system of the organization: what the users want to do with the technology and what changes in the learning and teaching processes and structures are brought about by the technology. Thus, implementation of ICT by organizations in general is a dynamic interaction between the processes, the technology, the people, and the organization. In the case of academic organizations, this complex process involves essential changes in the ways of thinking and professional practice of many and varied users. Many researchers have investigated these processes, and various models have been suggested to characterize and explain them in different types of organizations (Bates, 2000; Bonk, Cummings, Hara, Fischler, \& Lee, 2000; Harasim, 2000; Mioduser, Nachmias, Oren, \& Lahav, 1999; Owston, 1997).

In his book, Diffusion of Innovations (2003), Everett M. Rogers brings together a large number of studies in this area to create a general framework based on his definition of diffusion: "The process in which innovation is communicated through certain channels over time among the members of a social system" (p. 5). From this definition, Rogers derives four central elements of the diffusion process: innovation, the social system, communication channels, and time.

Rogers measures innovation according to five categories: Relative advantage - the extent to which an innovation is considered 'better' than the idea, practice, or object it is supposed to replace; Compatibility - the extent to which an innovation is consistent with existing values, previous experience, and the needs of potential users; Complexity - the extent to which the innovation is perceived as difficult to understand and complex to use; Trialability - the extent to which an innovation can be tested and experimented with on a limited scale; and Observability - the extent to which the use and effects of an innovation are visible to other members of the social system.

The social system is the environment within which the diffusion process takes place, and Rogers defines it as follows: "A set of interrelated units that are engaged in joint problem solving to accomplish a common goal" (2003, p. 24). According to Rogers, the structure of the communication networks within a social system exerts an important influence on the course of the diffusion process, as do the values and culture within the system and the various roles that members of the social system play within the system. Individual opinions, beliefs, attitudes, and behaviors often determine the degree of ICT adoption and implementation.

The role of time in the diffusion process manifests itself as a point in time when the individual decides to adopt the innovation. Time also plays a role in the rate of adoption. 


\section{Models Characterizing the Integration of Technologies into Teaching}

Rogers (2003) suggested a five-stage model for characterizing the process of change in organizations in general and the integration of new technologies into teaching in particular. The model emphasizes how the individual relates to the innovation, from the initial stage of awareness, through the stages of expressing interest, evaluation, and experiencing the new technology, to its adoption in the fifth stage.

Bouwman, van Dijk, van de Wijngaert, \& van Den Hooff (2005) distinguish between four perspectives from which to describe the process of adoption, implementation, use, and effect: the organizational, the technological, the economic, and the user perspective. There is considerable overlap between the various perspectives, and to some extent they are also mutually dependent. Yet each of these perspectives is important in explaining the course of the process; they operate on different levels and their importance varies at different points in time. The user perspective plays an important part in the implementation phase as well as in the use and effect phases. In addition, there is a difference in the level of analysis: economic and technical developments occur primarily in the organizational environment, while the user perspective plays a role on the individual level.

Bonk et al. (2000) focus on the integration of the Internet into teaching and suggest a model that describes the use of the Internet over a sequence of ten phases that define the extent of pedagogic use of the World Wide Web. Sandholtz, Ringstaff, and Dwyer (1997) and Mandinach and Cline (1994) propose a four-stage developmental model of professionalization in teaching and of assimilating ICT into teaching processes: survival, attainment of mastery, impact on the teaching process, and innovation.

\section{Promoting and Inhibiting ITC Adoption and Use}

Acknowledging the crucial role of individual attitudes and beliefs on the adoption, implementation, use, and effect of ICT, researchers also focus on factors that promote and inhibit the adoption of ICT in learning and teaching (U.S. Congress Office of Technology Assessment, 1995; Zhao \& Cziko, 2001). Scholars agree that a key factor is the need for a teacher to be motivated to use the technology: "Motivation is the catalyzing ingredient for every successful innovation" (Christensen, Horn, \& Johnson, 2008, p. 7).

Preston, Cox, and Cox (2000) raise two points: (1) The teacher must believe that the use of the technology can more effectively meet learning objectives or reach a higher level goal than could otherwise have been achieved; and (2) The teacher must feel that s/he has the confidence, ability, and access to necessary resources to apply the technology to the learning and teaching process.

Many studies have focused on aspects that encourage and support ICT use, such as the availability of resources, support and enthusiasm of colleagues, students' responses, time, availability of technical support, training received, opportunities, and realization of benefits of using ICT. These studies also relate to aspects that construct barriers to ICT implementation, such as availability of resources, lack of time, lack of confidence/knowledge, lack of training, and apathy or a negative attitude to ICT (Preston et al., 2000; Tearle, 2004; Zhao \& Cziko, 2001). Some of these barriers are external to teachers and are more resource-related. However, since in recent years computerbased technologies have become more and more available in educational settings, the more critical barriers to technology integration are internal to teachers (Ertmer, 2005; Hasselbring et al., 2000; Zhao, Pugh, Sheldon, \& Byers, 2002). Because the internal barriers usually lie within a teacher's underlying value system concerning learning and teaching, they are not easily identifiable as barriers. 
Ertmer (1999) used the classification of "first-order" and "second-order" barriers to describe the external and internal barriers to teacher technology integration. First-order barriers are those that are often seen initially as the obstacles, e.g., issues of adequate access to the technologies, training, and support, without which it is almost impossible to talk about technology integration.

However, overcoming these first-order barriers does not necessarily mean that technology integration and the effective and innovative use of technology will naturally follow. Second-order barriers are those that are embedded in a teacher's philosophy of teaching and learning; they are more hidden and deeply rooted in daily practice (Ertmer, 1999, 2005). Examples of second-order barriers are lack of vision or rationale for technology use, lack of relevance to the curriculum, and being incompatible with pedagogical beliefs. These barriers will inevitably result in ineffective use of the technologies.

In this research, we adopt Preston et al.'s (2000) classification of factors that influence the usage patterns of technology integration into two main clusters: external-environmental factors and internal-personal factors. External-environmental facilitating factors include elements such as existing training programs, technological and pedagogical support systems, and a good technological infrastructure. External inhibiting factors include significant time investment, lack of organizational rewards, and lack of a technological and pedagogical support system. Internal-personal factors include contributing factors such as users' positive attitudes toward ICT and their belief in the potential advantages of integrating ICT into teaching. Inhibiting internal factors are expressed in raising doubts about ICT and its contribution to learning and teaching.

\section{The Study}

The current study considers two of the central elements of the diffusion process mentioned by Rogers (2003): time and the social system. It focuses on the perspective of the course coordinators, the main force behind the implementation processes at the OUI. Course coordinators (CCs) are responsible for the academic and administrative planning and implementation of all course activities, including computer-mediated activities. Acknowledging that time plays a role, the current study was carried out after 10 years of substantial effort on the part of Shoham to integrate technologies into teaching. Between 1998 and 2008, an Internet-based learning environment was integrated into more than 600 academic courses (see Figure 1).

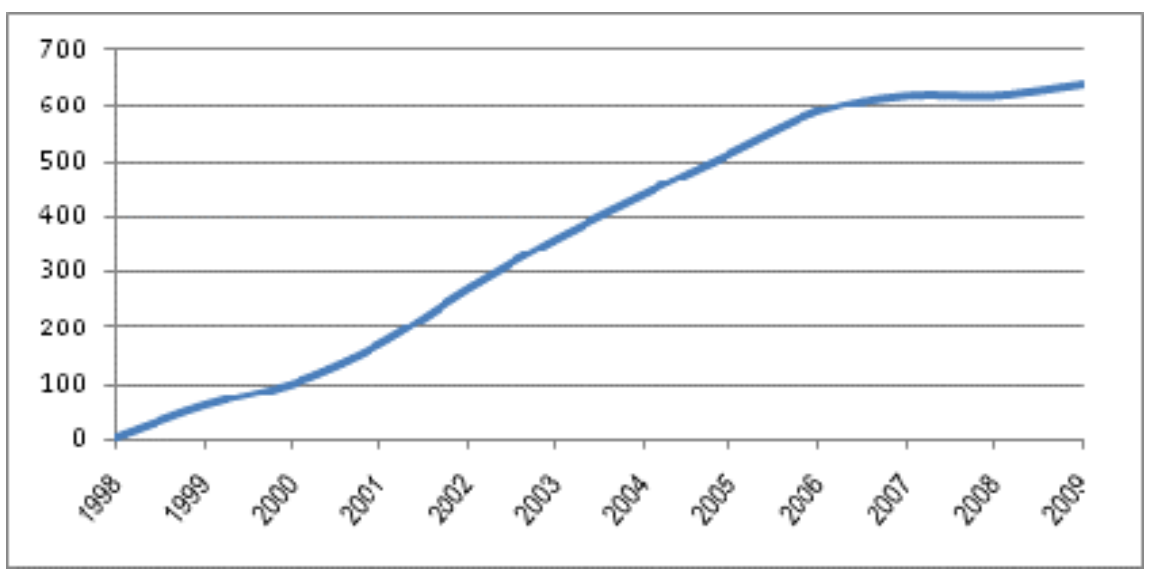

Figure 1. Growth in the number of internet-based courses

\section{The Conceptual Framework}

The conceptual framework of the research was based on the above theoretical background, and was used as the foundation for the evaluation process (see Figure 2). 


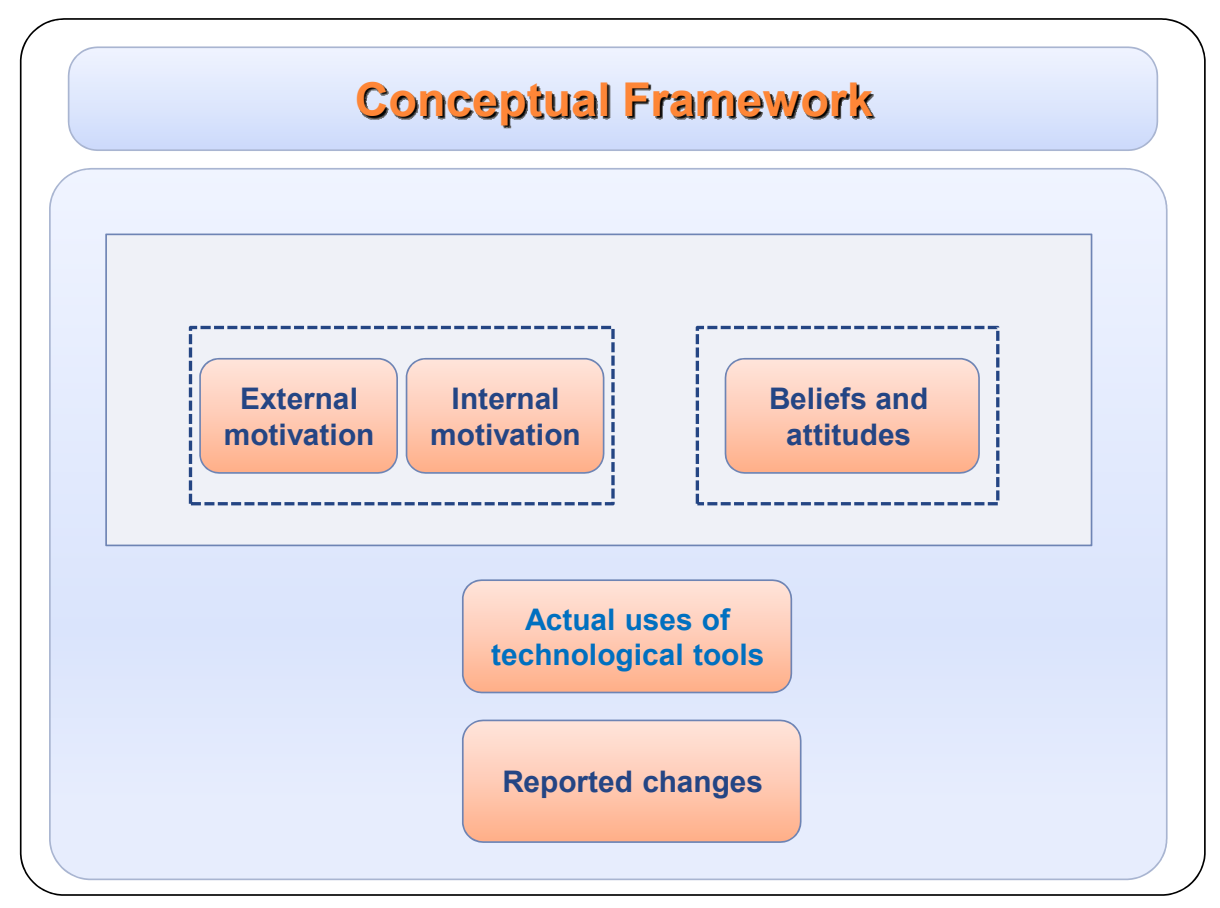

Figure 2. The conceptual framework of the study

The framework includes the following components:

1. Motivators that may promote or inhibit the implementation of technology in teaching: Internal motivators include attitudes and beliefs toward teaching and toward the contribution of technology to teaching processes; External motivators include system-wide policy and support, and provision of pedagogical and technological support systems.

2. The actual implementation of technology in teaching and course management.

3. The reported impact on pedagogical and administrative aspects of CCs' work; changes that took place after implementing technology.

Three evaluation questions emerged from this conceptual framework:

1. What internal and external motivators promote or inhibit the implementation of technology in teaching?

2. Which changes occurred after implementing technologies in learning, teaching, management, and communication?

3. What is the relation between the beliefs, attitudes, and motivation of course coordinators regarding the integration of technology into the learning and teaching processes and the selfreported changes in technology integration in academic teaching?

\section{Method}

\section{Participants}

The research sample included 285 CCs employed at the Open University during the spring semester of 2007. Findings are based on a sample of 128 CCs who completed the electronic questionnaire $(45 \%$ response rate). 


\section{Measures}

An electronic survey of attitudes, beliefs, and performance was emailed to all CCs. The survey included 100 items (multiple choice and open ended) and was developed by the authors in cooperation with Shoham staff members.

The four-part survey included:

1. Attitudes and beliefs (44 items measured on a 5-point Likert scale)

(a) 15 items regarding attitudes toward the use of technology in teaching in general and the issue of traditional (face-to-face) vs. nontraditional teaching

(b) 12 items regarding the level of importance attributed to integrating technology into academic teaching in relation to various teaching goals, even if at this stage the goals had not yet been achieved in their courses

(c) 17 items regarding factors that can enhance or inhibit the decision to integrate technology into teaching

2. Reported impact: 14 items (measured on a 5-point Likert scale) regarding the impact of the use of technology on pedagogical and administrative aspects of the CC's work. The respondents were asked to report to what extent their ongoing work as CCs changed as a result of using technology.

3. Implementation in practice: 36 items. Findings for this part will not be presented here.

4. Support by Shoham: 9 items regarding training, pedagogical guidance, and technological support. Findings for this part will not be presented here.

\section{Data Processing}

Factor Analysis was performed separately on the items of each part of the questionnaire to identify factors. These factors were used as the basis for constructing the indices. The internal reliability (Cronbach's $\alpha$ ) of the items composing each index was also taken into consideration in the final decision regarding the composition of each index. Here, we will relate only to the fourteen indices relevant to the research questions above:

1. Attitudes and beliefs -6 indices: Belief in the potential of technology ( 5 items, $\alpha=0.79$ ); skepticism concerning the contribution of the technology ( 5 items, $\alpha=0.69$ ); positive internal motivation ( 3 items, $\alpha=0.7$ ); inhibiting internal motivation ( 5 items, $\alpha=0.69$ ); positive external motivation ( 5 items, $\alpha=0.78$ ); inhibiting external motivation ( 5 items, $\alpha=0.81$ ).

2. Importance attributed to integrating technology into academic teaching in relation to various teaching goals -4 indices: communication and interactions through technology (3 items, $\alpha=0.79$ ); learning and teaching support ( 3 items, $\alpha=0.75$ ); provides a wealth of learning materials ( 3 items, $\alpha=0.69$ ); technological means as an alternative to face-to-face teaching ( 2 items, $\alpha=0.83$ );

3. Reported impact -4 indices: communication, interaction and transparency ( 5 items, $\alpha=$ 0.81 ); learning materials ( 2 items, $\alpha=0.77$ ); pedagogy ( 3 items, $\alpha=0.8$ ); course management (3 items, $\alpha=0.75)$.

\section{Findings}

1. Attitudes and beliefs of CCs regarding the use of technology in academic teaching at the OUI. 
Six indices were measured (see Figure 3): belief in the potential of technology in teaching; skepticism concerning technology in teaching; and four dimensions of the importance of technology: communication and interaction, learning support, learning materials, and substitute for face-toface teaching (for details, see the Appendix). The findings indicate that the level of belief in the potential of technology in teaching is significantly higher than the level of skepticism concerning technology in teaching (mean $=3.6$ and 2.9, respectively, $p<0.0001$ ). Regarding the importance attributed to technology, findings reveal that the respondents attribute the same high level of importance (mean $=4.2$ ) to the contribution of technology to communication and interaction, to learning materials and to learning support. The lowest level of importance is attributed to technological means as a substitute for face-to-face teaching (mean $=2.4 ; p<0.0001)$.

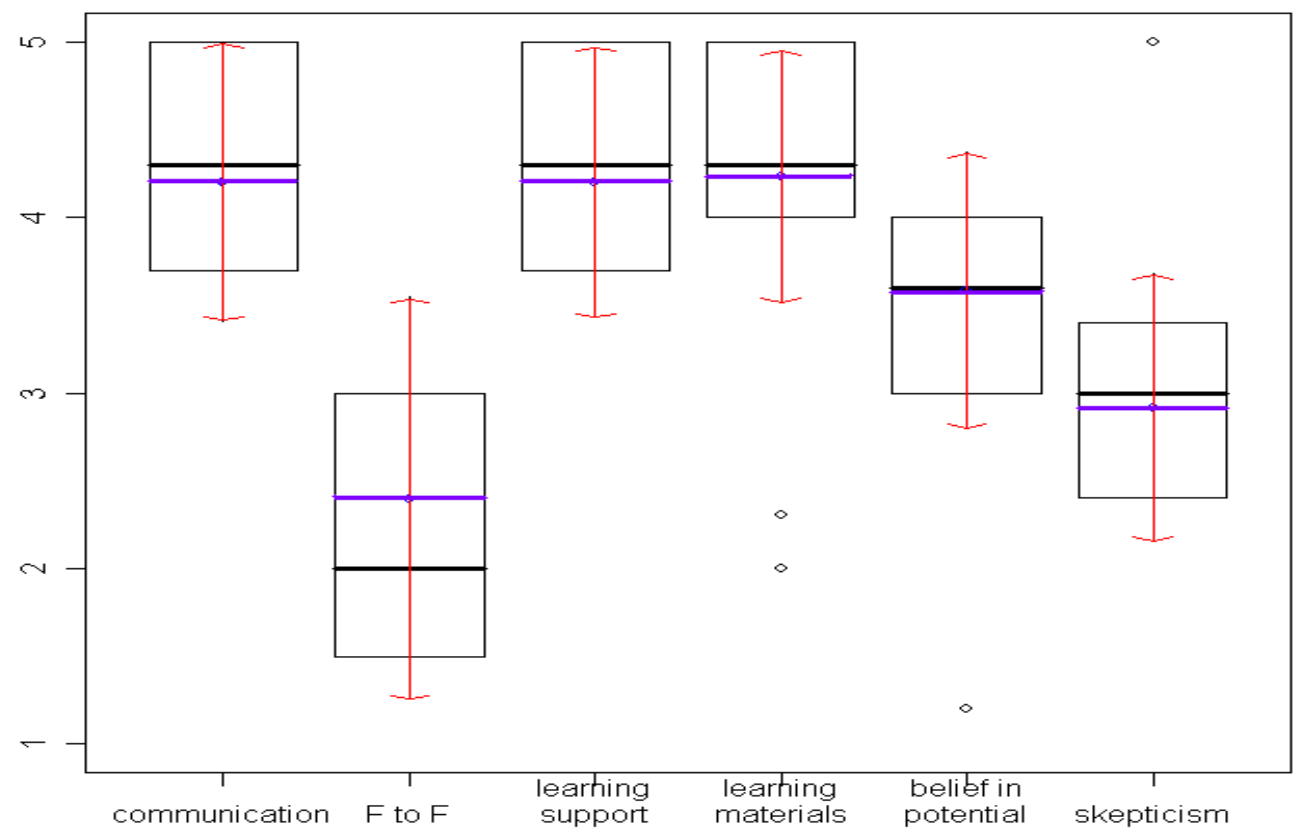
Average
Median
SD

Figure 3. The average, median and SD for the indices of attitudes and beliefs

2. Factors that enhance or inhibit the decision to integrate technology into course teaching

These were measured by four indices: internal-enhancing, internal-inhibiting, external-enhancing and external-inhibiting (for specifics, see the Appendix). The findings indicate that enhancing factors have significantly more influence than inhibiting factors $(p<0.0001)$. However, no significant differences were found between the level of influence of external vs. internal factors, either enhancing or inhibiting. Figure 4 shows the average, median, standard deviation and interquarterly range for each of the indices. 


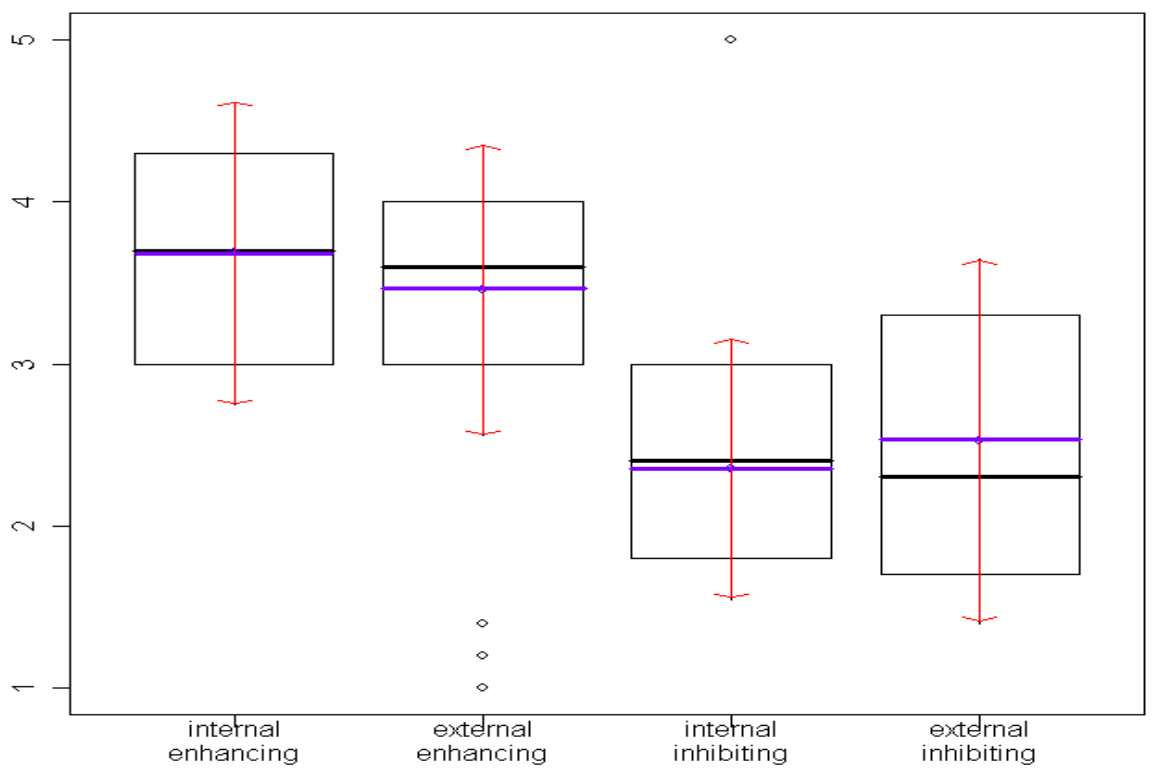

Figure 4. Average, median and SD of indices relating to the motivation for integrating technologies into teaching

3. Reported impact on learning, teaching, management and communication after implementing technologies.

Four indices measured changes in communication, learning materials, learning and teaching processes, and management (for details, see the Appendix). A comparative analysis of the 4 indices (see Figure 5) reveals that the two aspects in which the most significant changes occurred were communication (mean $=3.8)$ and learning materials $($ mean $=3.7)$. The smallest change occurred in pedagogy (mean $=2.2)$, significantly less than the change in the other areas $(p<0.0001)$. 


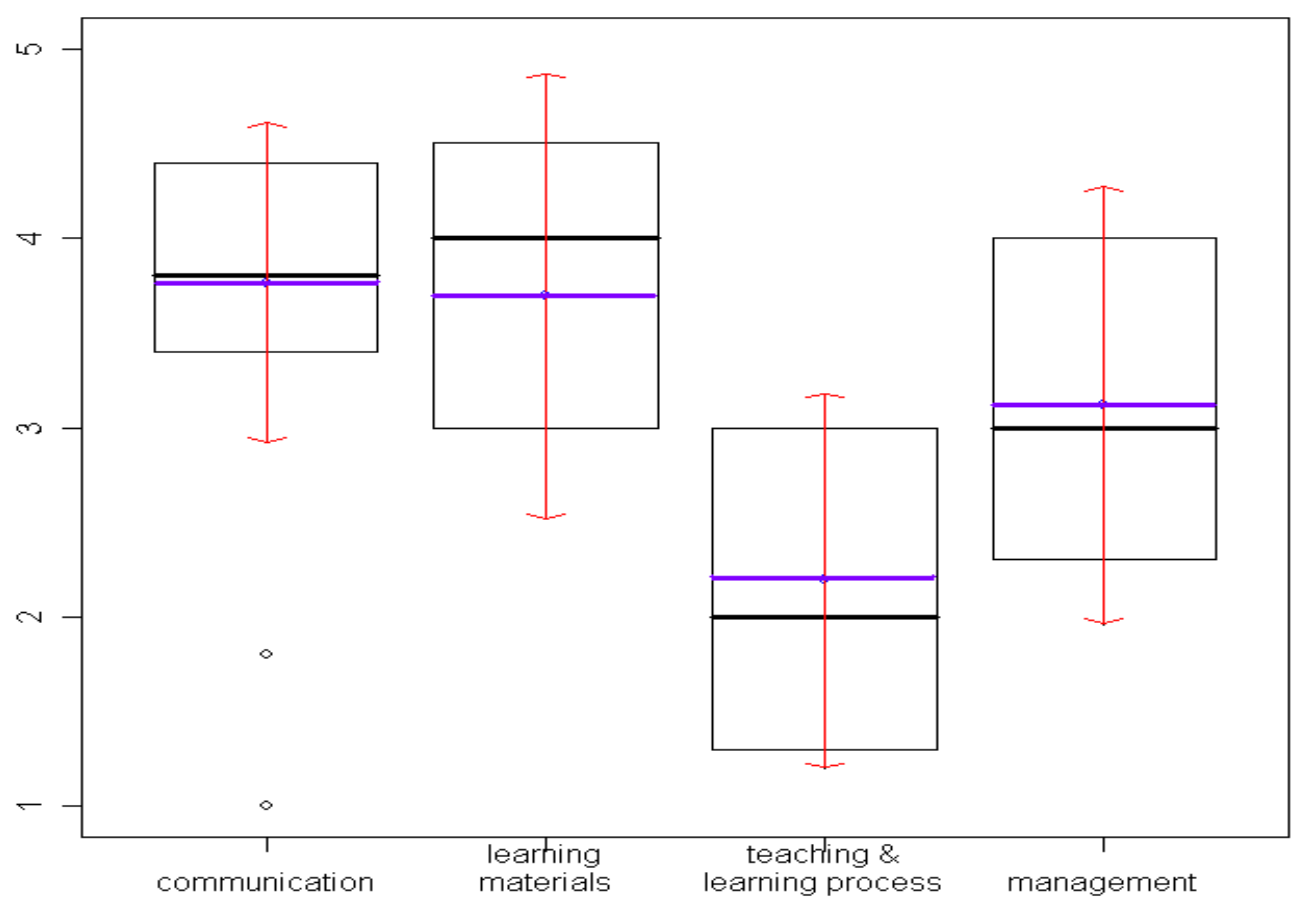

Figure 5: Average, median and SD of indices of change following the integration of technologies into teaching

\section{The Relation between Beliefs, Attitudes, and Motivation and Changes that Occurred Following the Integration of Technologies into Teaching}

Table 1 shows the correlations between the CCs' beliefs, attitudes, and motivation and the changes they reported as a result of integrating technology into their academic teaching.

Table 1. Pearson correlation coefficients between indices of attitudes, internal and external motivation and indices of reported change ( $\mathrm{N}$ in parentheses)

\begin{tabular}{|c|c|c|c|c|}
\hline $\begin{array}{l}\text { Reported changes following } \\
\text { the integration of } \\
\text { technologies }\end{array}$ & \multirow[t]{2}{*}{$\begin{array}{c}\text { Communication, } \\
\text { interaction and } \\
\text { transparency }\end{array}$} & \multirow[t]{2}{*}{$\begin{array}{l}\text { Learning } \\
\text { materials }\end{array}$} & \multirow[t]{2}{*}{ Pedagogy } & \multirow[t]{2}{*}{$\begin{array}{c}\text { Course } \\
\text { management }\end{array}$} \\
\hline Attitudes and beliefs & & & & \\
\hline Belief in the potential of ICT & $\begin{array}{c}0.329 * * \\
(101)\end{array}$ & $\begin{array}{l}0.299 * * \\
(101)\end{array}$ & $\begin{array}{l}0.303 * * \\
(105)\end{array}$ & $\begin{array}{l}0.190 \\
(104)\end{array}$ \\
\hline Skepticism & $\begin{array}{r}-0.230 * \\
(101) \\
\end{array}$ & $\begin{array}{c}-0.301 * * \\
(101)\end{array}$ & $\begin{array}{c}-0.333 * * \\
(105)\end{array}$ & $\begin{array}{r}-0.130 \\
(104) \\
\end{array}$ \\
\hline Internal enhancing & $\begin{array}{c}0.342 * * \\
(100)\end{array}$ & $\begin{array}{c}0.201 * \\
(100)\end{array}$ & $\begin{array}{l}0.111 \\
(104) \\
\end{array}$ & $\begin{array}{r}0.132 \\
(103)\end{array}$ \\
\hline Internal inhibiting & $\begin{array}{c}-0.313 * * \\
(101) \\
\end{array}$ & $\begin{array}{c}-0.355^{* *} \\
(101) \\
\end{array}$ & $\begin{array}{c}-0.311^{* *} \\
(105) \\
\end{array}$ & $\begin{array}{c}-0.398 * * \\
(104) \\
\end{array}$ \\
\hline External enhancing & $\begin{array}{r}-0.116 \\
(100) \\
\end{array}$ & $\begin{array}{r}-0.034 \\
(100) \\
\end{array}$ & $\begin{array}{r}-0.019 \\
(104)\end{array}$ & $\begin{array}{r}-0.015 \\
(103) \\
\end{array}$ \\
\hline External inhibiting & $\begin{array}{r}-0.037 \\
(101)\end{array}$ & $\begin{array}{r}-0.065 \\
(101)\end{array}$ & $\begin{array}{r}-0.061 \\
(105)\end{array}$ & $\begin{array}{r}-0.108 \\
(104)\end{array}$ \\
\hline
\end{tabular}

$* \mathrm{p}<0.05 * * \mathrm{p}<0.01 * * * \mathrm{p}<0.001$ 
The correlations demonstrate that:

A. Belief in the potential of technology is significantly positively correlated with three of the change indices: communication and interaction, learning materials, and pedagogy.

B. Skepticism concerning the contribution of technology is significantly negatively correlated with the same three indices, as expected from A above.

C. Significantly positive correlations were found between the internal enhancing motivation index and two of the reported change indices: communication and learning materials.

D. Significantly negative correlations were found between the internal inhibiting motivation index and all four reported change indices: communication, learning materials, pedagogy, and course management.

E. No significant correlations were found between external motivation indices (enhancing or inhibiting) and any of the reported change indices.

F. Reported changes in course management were significantly correlated only with internal inhibiting motivators.

\section{Discussion and Conclusions}

Introducing technology into distance teaching sounds like such a logical progression as to be almost trivial. However, even in an academic distance-teaching environment that can seemingly only be enhanced by the use of technologies, their adoption and implementation are not automatic. This study illustrates course coordinators' perceptions of utilizing technology in academic teaching and identifies factors that enhance or inhibit the adoption of technology, as well as the relationship between these factors and changes in teaching practice. It thus provides a better understanding of what needs to be done to broaden the use of technology in distance teaching. Three key findings emerged:

1. The CCs' attitude toward technology is generally positive; their belief in the potential of technology in teaching is higher than their level of skepticism. Furthermore, the level of enhancing factors - both internal and external - is higher than of inhibiting factors in determining their decision to integrate technology into teaching.

2. The main changes in the learning and teaching environment relate to aspects of communication with students (more intensive and more extensive) and learning materials (students are exposed to a richer variety and more updated materials).

3. There are significant positive correlations between the CCs' positive attitude and the internal enhancing motivators with changes in communication and interaction, learning materials, and pedagogy that occurred after implementing the technologies. These findings were supported by the significantly negative correlation between the level of skepticism concerning technology and these change indices.

After ten years of implementation of technological means into instruction at the Open University of Israel, our results indicate that the CCs are past the initial stages of adopting technological change, as described by Rogers (2003), Bonk et al. (2000), and Mandinach and Cline (1994). The CCs seem to have mastered the use of the standard technologies and are not apprehensive about the technological innovations; they do not object, are generally not skeptical, and do not emphasize the disadvantages of the use of technology - all of which characterize the initial stages of the integration of technology into teaching. The findings also indicate that the $\mathrm{CCs}$ believe that integration of technologies into teaching is a vital part of academic teaching at the OUI, and not only on a declarative level. 
In this study, the individual attitude to technology was almost positive, with only a minor indication of a hindering factor; there was a strong suggestion that technology had "arrived" and was now more visible. This supports Roger's (2003) claim about the importance of what he described as "observability," as well as Dawes' (1999) argument that teachers are not deliberately negative but need to see the value of new initiative clearly.

The finding that the majority of CCs at the OUI do not consider the online alternative as sufficiently worthy of replacing traditional face-to-face teaching corresponds to what is known about attitudes and practice of faculties at other institutes of higher education (Kurtz, Sagee, \& GetzLengerman, 2003; Nachmias, Ram, \& Mioduser, 2006). In the "pre-technology" era, face-to-face teaching at the OUI consisted of periodical tutorial sessions in various formats - weekly (intensive tutoring) or once every 2-3 weeks (regular tutoring) over a semester. The discussion forums, recorded lectures on video, and video-conferencing, all transmitted via the course websites, can replace face-to-face sessions or serve as enrichment. CCs at the OUI seem to favor a "blended learning" model, which falls between the enrichment model and the blended model as defined by Harasim, Hiltz, Teles and Turoff (1995). Some scholars claim that the blended model is probably the preferable and most achievable model in academic learning and teaching (Ginns \& Ellis, 2007).

A recent systematic meta-analysis and review of online learning studies from 1996 to 2008 performed by the U.S. Department of Education (Means, Toyama, Murphy, Bakia, \& Jones, 2009) found that instruction combining online and face-to-face elements had more advantages relative to purely face-to-face instruction than did purely online instruction. An important issue to keep in mind in reviewing these findings is that many studies did not attempt to equate (a) all the curriculum materials, (b) aspects of pedagogy, and (c) learning time in the treatment and control conditions. Indeed, some authors asserted that it would be impossible to do so. Hence, the observed advantage of online learning in general, and blended learning in particular, is not necessarily rooted in the media used per se and may reflect differences in content, pedagogy, and learning time.

We found no correlation between external motivators and technology implementation. Thus, internal motivators seem to be the essential force behind the changes reported by the CCs. While overcoming the external inhibitors is critical, it is more difficult and takes longer to overcome the internal barriers, since this requires that individuals change their attitudes, beliefs, and behaviors. As mentioned above, when teachers' beliefs and attitudes are incompatible with technologymediated change, this is a major barrier to effective integration of technology. The main difficulty in overcoming such barriers is that people tend to resist change when their old assumptions and values are challenged. Thus, they need to "experience conflict within their expectations" primarily when the new technology requires a change in their pedagogy (Wetzel, 2001).

It seems that the CCs at the OUI are in the final stage of the initial process of adapting and implementing technology to their pedagogical routine. The majority of the respondents have reached at least what Mandinach and Cline (1994) refer to as the "Mastery Stage." Technology is now an integral part of their teaching practice, whether used in the context of teaching materials, teaching aids, course management and communication with students and colleagues, or as an alternative to face-to-face teaching. Many of the CCs are now at Mandinach and Cline's "Impact Stage," where different applications of the technology are integrated into teaching and management processes, and these applications embrace a greater part of the curriculum. However, we found that most of the CCs reported minimal changes in core areas of the learning and teaching process: integrating technology has not changed the teaching itself or student assignments. Likewise, no change is evident in students' academic achievements following the implementation of technology. Many researchers consider this finding to be the essential problem of integrating technology into learning and teaching, as pointed out by Jochems, van Merrienboer and Koper (2004, p. 202): "Cur- 
rently, the most important issue with regard to integrated e-learning is the almost complete absence of a useful pedagogy. As a result teachers tend to fall back on traditional pedagogies." Accordingly, findings of the current study affirm that CCs at the OUI are still struggling with the opportunities and limitations of technology in teaching.

According to Bonk et al. (2000) and Mandinach and Cline (1994), the most advanced stage of technology integration is the "Innovation Stage," which focuses on the restructuring of the curriculum, making the Internet essential and obligatory in learning and teaching the course content, and ultimately producing a fully online course. Though the OUI is far from this stage, Shoham is actively involved in the development of alternative distance learning methodologies and models and the assessment of the use of technological and pedagogical alternatives. Having found that positive attitudes toward technology on the part of CCs are correlated with various changes, there is every reason to expect that, given guidance and support, the CCs will continue to adopt innovative technologies and complement them with changes in practice. These changes will be examined in future studies.

As noted above, not all the CCs have reached the same stage in the adoption of technologies. It is important to note that even though individuals tend to follow a sequence of stages of change when faced with the challenge to adopt an innovation, when facing the same innovation, people within an organization can belong to different stages of change due to the individual differences such as background and experience. Rogers suggests that the stages of change can "serve to classify individuals into segments on the basis of their readiness for behavior change, with a different program tailored to each individual" (2003, p. 201). Understanding the CCs' stages of change in terms of technology integration can help identify their needs and motivation in a timely manner and can thus expedite a more effective process of technology integration.

On the basis of the above, it is important to emphasize that it is the interaction and mutual influence between user, organization, and technology that shape the process of adoption, implementation, use, and effects of ICT in the learning and teaching process. Our study focused on the CCs' perspective; it offers a potential basis for further research on the process of technology implementation in academic teaching. As Bouwman et al. (2005) note, a longitudinal, multi-level perspective and multiple methods using multiple sources of data are needed to help provide insight into the process of implementation of technologies in learning and teaching.

\section{References}

Bates, A. W. (2000). Managing technological change: Strategies for college and university leaders. San Francisco: Jossey-Bass.

Bonk, C. J., Cummings, J. A., Hara, N., Fischler, R., \& Lee, S. M. (2000). A ten level Web integration continuum for higher education. In B. Abbey (Ed.), Instructional and cognitive impacts of Web-based education (pp. 56-77). Hershey, PA: Idea Group Publishing.

Bouwman, H., van Dijk, J., van de Wijngaert, L., \& van Den Hooff, B. (2005). Information and communication technology in organizations: Adoption, implementation, use and effects. London: Sage Publications.

Christensen, C. M., Horn, M. B., \& Johnson, C. W. (2008). Disrupting class: How disruptive innovation will change the way the world learns. New York: McGraw Hill.

Dawes, L. (1999). First connections: Teachers and the national grid for learning. Computers \& Education, $33(4), 235-252$.

Ertmer, P. A. (1999). Addressing first- and second-order barriers to change: Strategies for technology integration. Educational Technology Research and Development, 47(4), 47-61. 
Ertmer, P. A. (2005). Teacher pedagogical beliefs: The final frontier in our quest for technology integration? Educational Technology Research and Development, 53(4), 25-39.

Ginns, P., \& Ellis, R. (2007). Quality in blended learning: Exploring the relationships between on-line and face-to-face teaching and learning. The Internet and Higher Education, 10(1), 53-64.

Guterman, E., Alberton, Y., Brickner, R., \& Sagi, R. (2008). Integrating ICT into teaching and learning at the Open University of Israel: Perspective of academic faculty. Ra'anana: Evaluation Department, The Open University of Israel.

Harasim, L. (2000). Shift happens: Online education as a new paradigm in learning. The Internet and Higher Education, 3(1-2), 41-61.

Harasim, L., Hiltz, S. R., Teles, L., \& Turoff, M. (1995). Learning networks: A field guide to teaching and learning. Cambridge MA: MIT Press.

Hasselbring, T. S., Smith, L., Glaser, C. W., Barron, L., Risko, V. J., Snyder, C., Rakestraw, J., \& Campbell, M. (2000). Literature review: Technology to support teacher development (No. ED448159). Washington, DC: National Partnership for Excellence and Accountability in Teaching.

Jochems, W., van Merriënboer, J., \& Koper, R. (Eds.). (2004). Integrated e-learning: Implications for pedagogy, technology and organization. London: RoutledgeFalmer

Kurtz, G., Sagee, R., \& Getz-Lengerman, R. (2003). Alternative online pedagogical models with identical contents: A comparison of two university-level courses. The Journal of Interactive Online Learning, 2(1). Retrieved from http://www.ncolr.org/jiol/issues/PDF/2.1.2.pdf

Mandinach, E. B., \& Cline, H. F. (1994). Classroom dynamics: Implementing a technology-based learning environment. Hillsdale, NJ: Lawrence Erlbaum.

Means, B., Toyama, Y., Murphy, R., Bakia, M., \& Jones, K. (2009). Evaluation of evidence-based practices in online learning: A meta-analysis and review of online learning studies. Washington, DC: U.S. Department of Education. Retrieved from http://www.ed.gov/rschstat/eval/tech/evidence-basedpractices/finalreport.pdf

Mioduser, D., Nachmias, R., Oren, A., \& Lahav, O. (1999). Web-based learning environments (WBLE): Current implementation and evolving trends. Journal of Network and Computer Applications, 22(4), 233-247.

Nachmias, R., Ram, J., \& Mioduser, D. (2006). The study of a campus-wide implementation of blended learning in Tel Aviv University. In C. J. Bonk \& C. R. Graham (Eds.), The handbook of blended learning: Global perspectives, local designs (pp. 374-386). San Francisco, CA: Wiley.

Owston, R. D. (1997). The World Wide Web: A technology to enhance teaching and learning? Educational Researcher, 26(2), 27-33.

Preston, C., Cox, M., \& Cox, K. (2000). Teachers as innovators: An evaluation of the motivation of teachers to use ICT. London: MirandaNet.

Rogers, E. M. (2003). Diffusion of innovations (5th ed.). New York: Free Press.

Sandholtz, J. H., Ringstaff, C., \& Dwyer, D. C. (1997). Teaching with technology: Creating studentcentered classrooms. New York: Teachers College Press.

Tearle, P. (2004). The implementation of ICT in UK secondary schools. University of Exeter. Retrieved from http://citeseerx.ist.psu.edu/viewdoc/download?doi=10.1.1.105.6268\&rep=rep1\&type=pdf

U.S. Congress Office of Technology Assessment. (1995). Teachers and technology: Making the connection (No. OTA-EHR-616). Washington, DC: U.S. Government Printing Office. Retrieved from http://www.coedu.usf.edu/itphdsem/eme7938/ota9541.pdf

Wetzel, D. R. (2001, June 25-27). A model for pedagogical and curricula transformation with technology. Paper presented at the National Educational Computing Conference, NECC 2001: Building on the Future, Chicago, IL. 
Zhao, Y., \& Cziko, G. A. (2001). Teacher adoption of technology: A perceptual control theory perspective. Journal of Technology and Teacher Education, 9(1), 5-30

Zhao, Y., Pugh, K., Sheldon, S., \& Byers, J. (2002). Conditions for classroom technology innovations. Teachers College Record, 104(3), 482-515.

\section{Appendix}

1. Internal factors -4 indices: Attitudes and general beliefs concerning the integration of technology into teaching: belief in the potential; skepticism; and internal contributing; and inhibiting motivators. The items included in each index are detailed below. The sorting of the items and their classification into categories was performed via factor analysis, as well as by checking the internal reliability.

Belief in the potential (Cronbach's $\alpha=0.79$ )

- The integration of technologies creates opportunities for learning and experiences that do not exist within the framework of traditional teaching/learning

- The integration of technologies can encourage and stimulate learning more than traditional teaching

- Technology-based teaching methods can be as effective as traditional teaching methods

- Technology has the potential for having a positive influence on teaching

- Technological tools contribute to independent learning

Skepticism concerning the contribution of technology (Cronbach's $\alpha=0.69$ )

- The integration of technologies into the teaching of the course does not produce a fundamental change in learning

- The main reason for the use of technologies for teaching is the fact that they exist and are available

- Technology should be integrated into teaching only in situations where traditional teaching cannot be implemented

- The idea of integrating technology is an interesting one; however, its implementation requires further research and examination

- A face-to-face meeting between the teacher and the learner is essential for effective teaching

Contributing internal motivators (Cronbach's $\alpha=0.70$ )

- The possibility of experiencing new teaching methods

- Belief in the contribution of technology to teaching

- Knowledge and insights from research in the area

Inhibiting internal motivators (Cronbach's $\alpha=0.69$ )

- The amount of work required for the integration of technology into teaching

- Incompatibility between the course content and the integration of technology ${ }^{1}$

- Preference for using a computer as little as possible

- The course has been taught up till now in an optimal manner, without technology

- Skepticism concerning the contribution of technology to teaching and learning

2. External factors -2 indices: contributing and inhibiting external motivators

\footnotetext{
${ }^{1}$ The item "Incompatibility between the course content and the integration of technology" is associated with the teaching staff's beliefs on teaching in general and on the optimal way of teaching the course content in particular. Consequently, this item is included as an internal motivator.
} 
Contributing external motivators (Cronbach's $\alpha=0.78$ )

- Students' reactions/requests

- Encouragement and involvement of the senior faculty

- Recommendations of other course coordinators

- Expectations by the head of your department that technology will be integrated

- Financial recompense / scope of position

Inhibiting external motivators (Cronbach's $\alpha=0.81$ )

- Lack of technical knowledge, how to operate the technology

- Lack of knowledge on how to effectively integrate technology into the teaching and learning process

- Incompatibility of the proposed tools with teaching needs ${ }^{2}$

3. Reported changes that occurred after implementing the technology -4 indices: Respondents were asked to grade the extent of their agreement with dictums describing changes in various aspects of the course coordinators' work, since they began using technology more intensively. Four factors were identified:

Communication, interaction and transparency (Cronbach's $\alpha=0.81$ )

- You are approached by more students / you get more questions from students

- The degree of transparency of your work as a course coordinator has increased

- The connection between the students and the teaching staff has become stronger

- The students' use of the website for learning purposes has increased

- Communication between the students and their peers has increased

Study materials (Cronbach's $\alpha=0.77$ )

- The students are exposed to more diversified study materials

- It's easier for you to update the study material

Pedagogy (Cronbach's $\alpha=0.80$ )

- The teaching method of the course content has changed

- The nature of the assignments has changed

- The students' achievements in your course have improved

Course management (Cronbach's $\alpha=0.75$ )

- It's easier for you to deal with managing the course

- Your work is more effective

- It's easier for you to maintain contact with academic advisors

${ }^{2}$ The item "Incompatibility of the proposed tools with teaching needs" is associated to a greater degree with the attitude toward the technological infrastructure that supports teaching: the tools themselves, their technical and applicational aspects and the extent of their contribution to teaching. It is therefore included as an external motivator. 


\section{Biographies}

Eva Guterman (Ph.D) is a faculty member in the Department of Education and Psychology at the Open University of Israel and a research staff member in the Evaluation Department. She was involved in the design and implementation of new distance teaching methods for teacher training programs and academic education. Her research interests are in the areas of design, development and evaluation of learning and teaching processes. Current projects include studies that evaluate the integration of ICT in academic curricula, and the process of change in implementing various advance technologies at the Open University of Israel. http://www.openu.ac.i1/Personal sites/evaguterman.html

Yael Alberton is a statistician (M.A, Applied Statistics) and researcher in the Evaluation Department at the Open University. As part of her job, she is involved in all aspects of the evaluation of academic projects aimed to test the implications and effectiveness of technology in teaching and learning. She has submitted many reports on such evaluation projects to the interested party at the Open University and she has published several academic papers in international conferences.

Relly Brickner (Ph.D) is the head of the Evaluation and Training departments at the Open University of Israel. As part of her job, she is involved in evaluation researches of academic projects aimed to test the implications and effectiveness of technology in teaching and learning. Her expertise is varied and includes: the implementation of change processes in educational systems, professional development of educational staffs including school teachers and university tutors and course coordinators and evaluation of educational innovations.

Ronit Sagi is a research assistant in the Evaluation Department at the Open University and M.Sc. student in Applied Statistics in the School of Mathematical Sciences, Tel-Aviv University. 